\title{
Practices and intravascular catheter infection during on- and off-hours in critically ill patients
}

\author{
Niccolò Buetti ${ }^{1,8^{*}}$ D, Stéphane Ruckly ${ }^{1}$, Jean-Christophe Lucet ${ }^{1,2}$, Arthur Mageau', Claire Dupuis ${ }^{1}$, \\ Bertrand Souweine ${ }^{4}$, Olivier Mimoz ${ }^{5,6,7}$ and Jean-François Timsit ${ }^{1,3}$
}

\begin{abstract}
Background: The potential relationship between intravascular catheter infections with their insertion during weekend or night-time (i.e., off-hours or not regular business hours) remains an open issue. Our primary aim was to describe differences between patients and catheters inserted during on- versus off-hours. Our secondary aim was to investigate whether insertions during off-hours influenced the intravascular catheter infectious risks.

Methods: We performed a post hoc analysis using the databases from four large randomized-controlled trials. Adult patients were recruited in French ICUs as soon as they required central venous catheters or peripheral arterial (AC) catheter insertion. Off-hours started at 6 P.M. until 8:30 A.M. during the week; at weekend, we defined off-hours from 1 P.M. on Saturday to 8.30 A.M. on Monday. We performed multivariable marginal Cox models to estimate the effect of off-hours (versus on-hours) on major catheter-related infections (MCRI) and catheter-related bloodstream infections (CRBSIs).

Results: We included 7241 patients in 25 different ICUs, and 15,208 catheters, including 7226 and 7982 catheters inserted during off- and on-hours, respectively. Catheters inserted during off-hours were removed after 4 days (IQR 2, 9) in median, whereas catheters inserted during on-hours remained in place for 6 days (IQR 3,10; $p<0.01$ ) in median. Femoral insertion was more frequent during off-hours. Among central venous catheters and after adjusting for wellknown risk factors for intravascular catheter infection, we found a similar risk between off- and on-hours for MCRI (HR $0.91,95 \% \mathrm{Cl} 0.61-1.37, p=0.65)$ and CRBSI (HR 1.05, 95\% Cl 0.65-1.68, $p=0.85)$. Among central venous catheters with a dwell-time $>4$ or $>6$ days, we found a similar risk for MCRI and CRBSI between off- and on-hours. Similar results were observed for ACs.
\end{abstract}

Conclusions: Off-hours did not increase the risk of intravascular catheter infections compared to on-hours. Off-hours insertion is not a sufficient reason for early catheter removal, even if femoral route has been selected.

Keywords: Catheter, Catheter-related bloodstream infection, Bloodstream infection, ICU, Off-hours, On-hours

\section{Background}

Intravascular catheters are instrumental in the care of intensive care unit (ICU) patients to allow safe intravenous administration of medications, enable the intravenous administration of fluid resuscitation and the monitoring of hemodynamic parameters. On one hand,

${ }^{*}$ Correspondence: niccolo.buetti@gmail.com

${ }^{1}$ University of Paris, INSERM, IAME, 75006 Paris, France

Full list of author information is available at the end of the article the central venous catheter utilization rate is high with an average of 70.1 catheter-days per 100 patient days reported in European ICU [1]. On the other hand, ICU-bloodstream infections (BSIs) are reported as catheter-related in one-fourth to one-third of cases [2]. Intravascular catheter-related infections are associated with increased costs, morbidity and mortality [3, 4]. A large proportion of intravascular catheter infection is preventable [5].
SpringerOpen

(c) The Author(s) 2021. Open Access This article is licensed under a Creative Commons Attribution 4.0 International License, which permits use, sharing, adaptation, distribution and reproduction in any medium or format, as long as you give appropriate credit to the original author(s) and the source, provide a link to the Creative Commons licence, and indicate if changes were made. The images or other third party material in this article are included in the article's Creative Commons licence, unless indicated otherwise in a credit line to the material. If material is not included in the article's Creative Commons licence and your intended use is not permitted by statutory regulation or exceeds the permitted use, you will need to obtain permission directly from the copyright holder. To view a copy of this licence, visit http://creativecommons.org/licenses/by/4.0/. 
Patients admitted to hospital during off-hours (i.e., during the night or at weekend) may experience poorer quality of care and clinical outcomes due to the reduced human resources. For example, mortality was higher in acute myocardial infarct patients admitted during weekend daytime hours when compared with patients admitted during other times [6]. The degree to which intravascular catheter infections were associated with weekend or night-time (i.e., off-hours) insertions reflects poorer quality of care remains an open issue. To our knowledge, no study has investigated the variations in clinical processes and risk of intravascular catheter infections between on- compared with offhours insertions.

Our primary aim was to describe differences between patients and catheters inserted during on-versus offhours. Our secondary aim was to investigate whether insertions during off-hours influenced the level of intravascular infectious risks.

\section{Material and methods Design}

We performed a post hoc analysis using the databases from four large randomized-controlled trials (RCTs; i.e., DRESSING1, DRESSING2, ELVIS and CLEAN). A prospective high-quality data collection was performed [7-10]. The similarities among all these RCTs concerning inclusion criteria and definitions allowed us to merge the four databases. The DRESSING1 investigated the effect of chlorhexidine gluconate (CHG) sponge-dressing for preventing intravascular catheter infections. The DRESSING2 study assessed the effect of CHG gel-dressing and highly adhesive dressing for preventing catheter-related infections and catheter colonization. The ELVIS study investigated the impact of intravascular catheter infection of preventive ethanol-based lock therapy in shortterm dialysis catheters. The CLEAN study evaluated differences in infectious complications between skin antisepsis either with 2\% alcoholic CHG and povidone iodine-alcohol [PVI]. CHG-dressings (i.e., sponge- or gel-dressing) and CHG-skin antisepsis decreased the risk of infection. However, ethanol-based lock did not reduce intravascular catheter infections. The study interventions were neither blinded to the ICU staff nor to the investigators; however, they were blinded to the microbiologists who processed the samples of skin, blood and catheter cultures and to the adjudication committee (see definitions). The current analysis complied with the STROBE guidelines for observational studies. The studies were approved by national ethic committees; further ethical consent was not required according to the French law for research.

\section{Patients}

Patients older than 18 years were recruited from 2008 to 2014 in French ICU as soon as they required central venous catheters, a short-term dialysis catheter (DC) or peripheral arterial (AC) catheter insertion. The characteristics of included patients were similar across studies. Patients underwent follow-up until death or $48 \mathrm{~h}$ after ICU discharge.

\section{Catheters}

This analysis evaluated data from patients with shortterm central venous catheters, ACs and DCs included in the four RCTs. Catheters without exhaustive information on time of insertion were excluded. All catheters were managed in the same way. Investigators complied with French recommendations for catheter insertion and care, which are similar to CDC guidelines [11] (Additional file 1), which are described elsewhere [12]. Of note, prevention strategies did not substantially change since 2014 [13]. Importantly, randomization process was carried out immediately before catheter insertion. Information on insertion time was routinely collected in all RCTs. Time of catheter removal catheters was decided by the attending physician caring for each patient.

\section{Definitions}

We used French definitions for intravascular catheter colonization and infections [14]. Catheter tip colonization was defined as a quantitative culture yielding $\geq 1000 \mathrm{cfu} / \mathrm{mL}$ [15]. A catheter-related bloodstream infection (CRBSI) was a combination of (1) one or more positive peripheral blood cultures sampled after at least $48 \mathrm{~h}$ of catheterization or maximal $48 \mathrm{~h}$ after catheter removal; (2) a blood culture differential time-to positivity of $2 \mathrm{~h}$ or more [16], or the isolation of the same phenotypic microorganism from the colonized catheter and (3) no apparent source of bloodstream infection (BSI) other than the catheter [7-10]. Catheter-related clinical sepsis without BSI was a combination of catheter colonization, body temperature, pus at the insertion site, or resolution of clinical sepsis after catheter removal, and the absence of any other infectious focus [17]. Major catheter-related infection (MCRI) was defined as either a CRBSI, or a catheter-related clinical sepsis without bloodstream infection. If a patient had a positive blood culture for coagulase-negative staphylococci (CoNS), two separate peripheral blood cultures had to grow the same microorganism that colonized the catheter tip. Alternatively, the same pulsotype from the strains recovered from the catheter tip and blood culture was required for a diagnosis of a CoNS-CRBSI. All suspected cases of catheterrelated infections were reviewed by masked independent 
assessors based on detailed pre-established definitions [7-10].

As time of catheter insertion was available, we created a variable for night and weekend insertions ("off-hours" or "not regular business hours"). Of note, in France, offhours started at 6 PM until 8:30 A.M. during the week. At weekend, we defined off-hours from 1 P.M. on Saturday to 8.30 A.M. on Monday. To ease the readability of manuscript, we simplified this variable in off- or on-hours.

During off-hours, in all ICUs, one senior physician (for a maximum of 20 ICU beds) and one resident are on duty. During on-hours, senior physician-to-patient ratio ranges from $1: 3$ to $1: 6$ and the resident-to-patient ratio ranges from 1:2 to 1:5.

Skin colonization at insertion site colonization at the time of catheter removal was evaluated in three studies using semi-quantitative insertion-site cultures: the insertion site was sampled immediately before catheter removal $[7,8,10]$. As previously analyzed $[12,18]$ and because the size of the insertion site cultured was different across studies, we created a semi-quantitative variable with sterile, low-grade colonization, and high-grade colonization according to the median of quantitative cultures obtained in each study.

\section{Statistical analysis}

Characteristics of patients and catheters were described as median (interquartile range, IQR) or count (percent) for quantitative and qualitative variables, respectively. For group comparison, we used Chi-square or Fisher and Wilcoxon tests as appropriate.

We performed marginal Cox models for clustered data, in order to take into account a possible clustering effect of multiple catheters per patient and stratifying by center. Data were censored at 28 days after catheter insertion. Hazard ratio (HR) for MCRI, CRBSI or catheter tip colonization was evaluated by multivariate analysis. The variable off-hours (versus on-hours) was forced in the multivariate models and other relevant well-known intravascular catheter infection risk factors were used as adjustment variables. The following adjustment variables were selected: gender, SAPS II, insertion site, experience of the operator, skin antisepsis (alcoholic chlorhexidine gluconate [CHG] versus povidone iodine), CHG-impregnated dressings (either sponge- or gel-dressings versus non-impregnated dressings), time from ICU admission to catheter insertion, mechanical ventilation and vasopressor at insertion. The effect of "off-hours" on MCRI, CRBSI and catheter tip colonization was estimated. A hazard ratio $(\mathrm{HR})>1$ indicated an increased risk for off-hours compared to on-hours. This marginal Cox model we used considers the intra-cluster dependency (i.e., more than one catheter per patient), using robust sandwich covariance estimates (PROC PHREG of SAS) [19]. The proportionality of hazard for off-hours was tested using Martingale residuals. Analyses were separated for central venous catheters and ACs. We pooled both central venous catheters and DCs in the same variable (i.e., CVC). We performed several additional analyses: (1) we analyzed the risk of intravascular catheter infections between off- and on-hours for catheters inserted more than 4 days or 6 days; (2) we assessed whether femoral insertions during off-hours were associated with increased risk in non-subclavian catheters; (3) we performed a sensitivity analysis excluding the first inserted intravascular central venous catheter or excluding patients admitted for planned surgery using MCRI as an outcome. Tests were two-tailed, with $p<0.05$ being considered significant. All analyses were performed using SAS (version 9.4). Further details on randomization groups or missing data were available in the Additional file 1.

\section{Results \\ Patients and catheters}

Between 2009 and 2014, we included 7241 patients and 15,208 catheters from 25 different ICUs (Fig. 1). We monitored 6338 ACs, 6142 central venous catheters and 2,28 DCs.

Catheters inserted during off- and on-hours were 7226 and 7982, respectively. Characteristics of patients and catheters are illustrated in Tables 1 and 2. Overall, patients with catheter insertions during on-hours were similar to patients with off-hours insertions. Catheters inserted in solid organ transplant patients were more frequently inserted during on-hours $(4.5 \%$ versus off-hours $3.3 \%, p=0.02)$. ICU mortality was similar between both groups.

Catheters inserted during off-hours were removed after 4 days (IQR 2, 9) in median, whereas catheters inserted during on-hours remained in place for 6 days (IQR 3,10; $p<0.01)$ in median. Dwell-time among first inserted catheters were again shorter in the off-hours group (4 days, IQR 2,8$)$ compared to the on-hours group (5 days [IQR $2,9], p<0.01$ ). Junior operators (i.e., $<50$ procedures) inserted intravascular catheters more frequently during on-hours $(64.9 \%)$ compared to off-hours $(56.8 \%, p<0.01)$. The choice of insertion site changed between on- and offhours, with femoral insertions being more frequent during off-hours for $\mathrm{AC}$, central venous catheter and DC. Interestingly, no major percentage (less than $2.2 \%$ ) differences in reasons for catheter removal were observed between the two groups. Suspicion of infection were more frequently observed in catheters inserted during on-hours $(14.2 \%$ versus off-hours $12.2 \%, p<0.01)$. We observed 88 (1.1\% or 1.50 per 1000 catheter-days), 60 


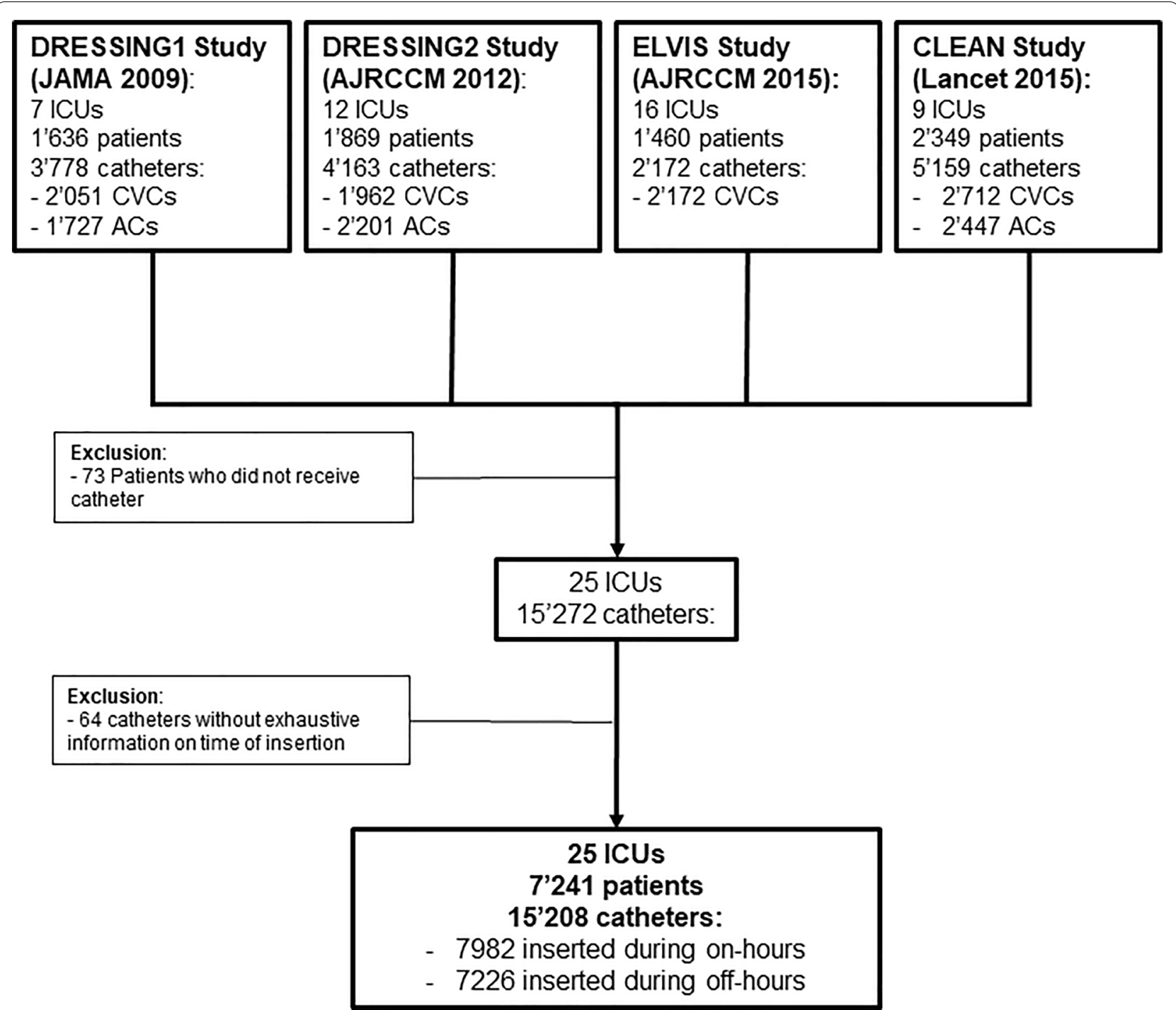

Fig. 1 Flowchart. ICU: intensive care unit. CVC: central venous catheters and short-term dialysis catheters. AC: arterial catheter

( $0.8 \%$ or 1.02 per 1000 catheter-days) and $653(8.2 \%$ or 11 per 1000 catheter-days) MCRI, CRBSI and catheter tip colonization in the on-hours group, respectively. We observed 67 ( $0.9 \%$ or 1.47 per 1000 catheter-days), $48(0.7 \%$ or 1.02 per 1000 catheter-days) and 540 (7.5\% or 12 per 1000 catheter-days) MCRI, CRBSI and catheter tip colonization during off-hours, respectively. No differences in MCRI, CRBSI and catheter tip colonization prevalence were observed between the two groups.

\section{Infectious risk for off-hours in CVCs}

Among CVCs and after adjustment for well-known risk factors for intravascular catheter infection, we found a similar risk between off- and on-hours for MCRI (HR 0.91, 95\% CI 0.61-1.37, $p=0.65$ ), CRBSI (HR 1.05, 95\% CI $0.65-1.68, p=0.85$ ) and catheter tip colonization (HR 1.04, 95\% CI 0.90-1.21, $p=0.59$, Fig. 2). Among CVCs with a dwell-time $>4$ days, we found a similar risk between off- and on-hours for MCRI (HR 0.82, 95\% CI 0.52-1.2, $p=0.39$ ), CRBSI (HR 0.92, 95\% CI 0.53-1.59, $p=0.76$ ) and catheter tip colonization (HR 0.97, 95\% CI 0.81-1.16, $p=0.74$ ). Among CVCs with a dwell-time $>6$ days, we found a similar risk between off- and on-hours for MCRI (HR 0.77, 95\% CI 0.47-1.27, $p=0.31$ ), CRBSI (HR 0.76, 95\% CI $0.42-1.39, p=0.38)$ and catheter tip colonization (HR 0.97, 95\% CI 0.79-1.20, $p=0.79$ ). Among non-subclavian CVCs inserted during off-time, the 
Table 1 Patients characteristics $(n=5548)$

\begin{tabular}{|c|c|c|c|c|}
\hline & & On-hours & Off-hours & $p$-value* \\
\hline Sex & Female & $996(35.4)$ & $1,007(36.8)$ & 0.27 \\
\hline Age, median [IQR] & & $64[53 ; 74]$ & $65[53 ; 75]$ & 0.06 \\
\hline Without comorbidity & & $1,602(56.9)$ & $1,586(58)$ & 0.43 \\
\hline Chronic renal failure & & $143(5.1)$ & $129(4.7)$ & 0.53 \\
\hline Chronic heart failure & & $208(7.4)$ & $199(7.3)$ & 0.87 \\
\hline Diabetes & & $225(8)$ & $224(8.2)$ & 0.79 \\
\hline Chronic respiratory failure & & $153(5.4)$ & $140(5.1)$ & 0.59 \\
\hline HIV & & $65(2.3)$ & $57(2.1)$ & 0.57 \\
\hline Solid organ transplant & & $127(4.5)$ & $91(3.3)$ & 0.02 \\
\hline Other immunosuppression & & $176(6.3)$ & $158(5.8)$ & 0.45 \\
\hline Hematological malignancy & & $151(5.4)$ & $146(5.3)$ & 0.96 \\
\hline \multirow[t]{12}{*}{ Reason for ICU admission } & Septic shock & $590(21)$ & $619(22.6)$ & $<0.01$ \\
\hline & Planned surgery & $126(4.5)$ & $60(2.2)$ & \\
\hline & Trauma & $148(5.3)$ & $142(5.2)$ & \\
\hline & Abdominal MOF & $96(3.4)$ & $77(2.8)$ & \\
\hline & Cardiac shock & $208(7.4)$ & $266(9.7)$ & \\
\hline & Hemorrhagic shock & $125(4.4)$ & $125(4.6)$ & \\
\hline & Shock (other) & $73(2.6)$ & $83(3)$ & \\
\hline & Respiratory failure & $666(23.7)$ & $540(19.7)$ & \\
\hline & COPD exacerbation & $65(2.3)$ & $50(1.8)$ & \\
\hline & Renal failure & $191(6.8)$ & $253(9.3)$ & \\
\hline & Coma & $266(9.5)$ & $280(10.2)$ & \\
\hline & Continuous surveillance & $259(9.2)$ & $240(8.8)$ & \\
\hline Mechanical ventilation in the first $24 \mathrm{~h}$ & & $2037(72.4)$ & $1948(71.2)$ & 0.33 \\
\hline SAPS II, median [IQR] & & $54[39 ; 69]$ & $54[41 ; 71]$ & 0.07 \\
\hline SOFA score, median [IQR] & & $10[7 ; 14]$ & $10[7 ; 14]$ & 0.53 \\
\hline ICU mortality & & $909(32.3)$ & $905(33.1)$ & 0.54 \\
\hline ICU length of stay, median [IQR] & & $9[5 ; 18]$ & $7[4 ; 13]$ & $<0.01$ \\
\hline
\end{tabular}

1,693 patients had both insertion during the night and day and were excluded from this analysis. Data were expressed in $\mathrm{n}$ (percentage) or median [interquartile range]. ${ }^{*}$ Without adjustment

femoral site was not associated with an increased risk of MCRI (HR 0.97, 95\% CI 0.48-1.96, $p=0.94$ ) and CRBSI (HR 0.92, 95\% CI 0.43-1.96, $p=0.83$ ). However, the risk of catheter tip colonization for femoral insertions was increased compared to jugular insertions (HR 1.57, 95\% CI 1.20-2.07, $p=0.0012$ ) during off-hours.

Sensitivities analyses excluding the first inserted CVC or excluding patients admitted for planned surgery using MCRI as an outcome are illustrated in the Additional file 1 and showed similar results.

\section{Infectious risk for off-hours in ACs}

After adjustment for well-known risk factors for intravascular catheter infection, the level of risk was similar between off- and on-hours for MCRI (HR 1.49, 95\% CI 0.84-2.62, $p=0.17$ ), CRBSI (HR 1.21, 95\% CI 0.59-2.47, $p=0.61$ ) and catheter tip colonization (HR 1.16, 95\% CI 0.97-1.40, $p=0.10$, Fig. 2). Among ACs with a dwelltime $>4$ days, the level of risk was also similar between off- and on-hours for MCRI (HR 1.50, 95\% CI 0.79-2.84, $p=0.21$ ), CRBSI (HR 1.49, 95\% CI 0.69-3.23, $p=0.31$ ) and catheter tip colonization (HR 1.10, 95\% CI 0.89-1.36, $p=0.39$ ). Among ACs with a dwell-time $>6$ days, the level of risk was also similar (data not shown). Among ACs inserted during off-time, the femoral site was not associated with an increased risk of MCRI (HR 0.85, 95\% CI 0.31-2.33, $p=0.75$ ) and CRBSI (HR 0.61, 95\% CI $0.17-2.15, p=0.44)$. Catheter tip colonization risk was increased for femoral insertions compared to radial insertions (HR 1.74, 95\% CI 1.31-2.31, $p=0.0001$ ) during off-hours.

\section{Skin colonization at catheter removal between on- and off-hours}

Skin colonization at insertion site colonization at the time of catheter removal (variable available for 9478 catheters) was more frequently colonized in the on-hours group compared to the off-hours $(p<0.01$, Table 3$)$. Considering 
Table 2 Catheters characteristics $(n=15,208)$

\begin{tabular}{|c|c|c|c|c|}
\hline Catheters ( $n=15,208)$ & & On-hours & Off-hours & $p$-value** \\
\hline Catheter-days, median [IQR] & & $6[3 ; 10]$ & $4[2 ; 9]$ & $<0.01$ \\
\hline First catheter & & $3494(43.8)$ & $3661(50.7)$ & $<0.01$ \\
\hline Experience level of the operator & $<50$ procedures & $5184(64.9)$ & $4101(56.8)$ & $<0.01$ \\
\hline \multirow[t]{2}{*}{ Insertion site for AC } & Femoral & $1076(33.4)$ & $1176(37.7)$ & $<0.01$ \\
\hline & Radial & $2144(66.6)$ & $1942(62.3)$ & \\
\hline \multirow[t]{3}{*}{ Insertion site for central venous catheter } & Jugular & $1084(33.6)$ & $875(30)$ & $<0.01$ \\
\hline & Subclavian & $1264(39.1)$ & $951(32.6)$ & \\
\hline & Femoral & $881(27.3)$ & $1087(37.3)$ & \\
\hline \multirow[t]{3}{*}{ Insertion site DC } & Jugular & $581(37.9)$ & $327(27.4)$ & $<0.01$ \\
\hline & Subclavian & $24(1.6)$ & $11(0.9)$ & \\
\hline & Femoral & $928(60.5)$ & $857(71.7)$ & \\
\hline \multirow[t]{2}{*}{ Catheter type for central venous catheter } & CVC & $3229(67.8)$ & $2913(70.9)$ & $<0.01$ \\
\hline & DC & $1533(32.2)$ & $1195(29.1)$ & \\
\hline Ultrasound guidance* & & $857(17.9)$ & $695(16.1)$ & 0.02 \\
\hline CHG-impregnated dressings & & 2055 (25.7) & $1991(27.6)$ & 0.01 \\
\hline Skin antisepsis with CHG & & $3640(45.6)$ & $3263(45.2)$ & 0.58 \\
\hline Mechanical ventilation at insertion & & $6108(76.5)$ & $5399(74.7)$ & $<0.01$ \\
\hline Vasopressor at insertion & & $4138(51.8)$ & $3958(54.8)$ & $<0.01$ \\
\hline Antibiotics at insertion & & $5171(64.8)$ & $4396(60.8)$ & $<0.01$ \\
\hline \multirow[t]{7}{*}{ Reason for removal } & Death & $1730(21.7)$ & $1649(22.8)$ & 0.09 \\
\hline & No longer needed & $2371(29.7)$ & $2277(31.5)$ & 0.02 \\
\hline & Suspicion of infection & $1133(14.2)$ & $881(12.2)$ & $<0.01$ \\
\hline & ICU discharge & $1728(21.6)$ & $1647(22.8)$ & 0.09 \\
\hline & Bleeding & $18(0.2)$ & $8(0.1)$ & 0.09 \\
\hline & Wrenched & $111(1.4)$ & $103(1.4)$ & 0.86 \\
\hline & Dysfunction*** & $711(11.7)$ & $584(10.9)$ & 0.19 \\
\hline MCRI & & $88(1.1)$ & $67(0.9)$ & 0.28 \\
\hline CRBSI & & $60(0.8)$ & $48(0.7)$ & 0.52 \\
\hline Catheter tip colonization & & $653(8.2)$ & $540(7.5)$ & 0.10 \\
\hline
\end{tabular}

* Missing information in 6107 catheters (i.e., DRESSING1 and ELVIS studies). Data were expressed in $\mathrm{n}$ (percentage) or median [interquartile range]. ** Without adjustment. **** This information was available only for the DRESSING2, CLEAN and ELVIS study but not for the DRESSING1 study (total missing data $\mathrm{n}=3778$ )

only catheters with $\leq 4$ days of maintenance $(n=4129)$, no significant difference was observed between on- and off-hours groups $(p=0.11)$.

\section{Discussion}

Using high-quality data from four RCTs, this post hoc analysis showed that intravascular catheters inserted during off-hours were removed earlier on, and were more frequently inserted in femoral sites compared to catheters inserted during on-hours. Off-hours insertions did not increase the risk of intravascular catheter infections and the femoral site did not substantially increase the infectious risk during off-hours. Although several outcomes (i.e., mortality, surgical site infections) according to the time of admission or intervention were assessed [20-23], to our knowledge, this is the first study that addressed this topic for intravascular catheter infections.
Catheters removal was performed earlier if inserted during off-hours. Reasons for removal between on- and off-hours showed similar percentages. We found a decreased dwell-time for off-hours catheters after exclusion of the first insertions or patients admitted for planned surgery. Interestingly, this finding was not related to a more frequent suspicion of infection at the time of catheter removal. We therefore suppose that catheters inserted during off-hours were more frequently removed for clinician's fear of possible contamination. However, we cannot exclude a longer administration of catecholamine for catheters inserted during on-hours. Interestingly, skin at exit site at removal in catheters inserted during off-hours was less colonized compared to catheters inserted during on-hours, thus possibly reflecting a premature removal for off-hours-inserted catheters. Similar 
Adjusted MCRI risk for off-hours in CVC

Adjusted CRBSI risk for off-hours in CVC

Adjusted colonization risk for off-hours in CVC

Adjusted MCRI risk for off-hours in AC

Adjusted CRBSI risk for off-hours in AC

\section{Adjusted colonization risk for off-hours in AC}

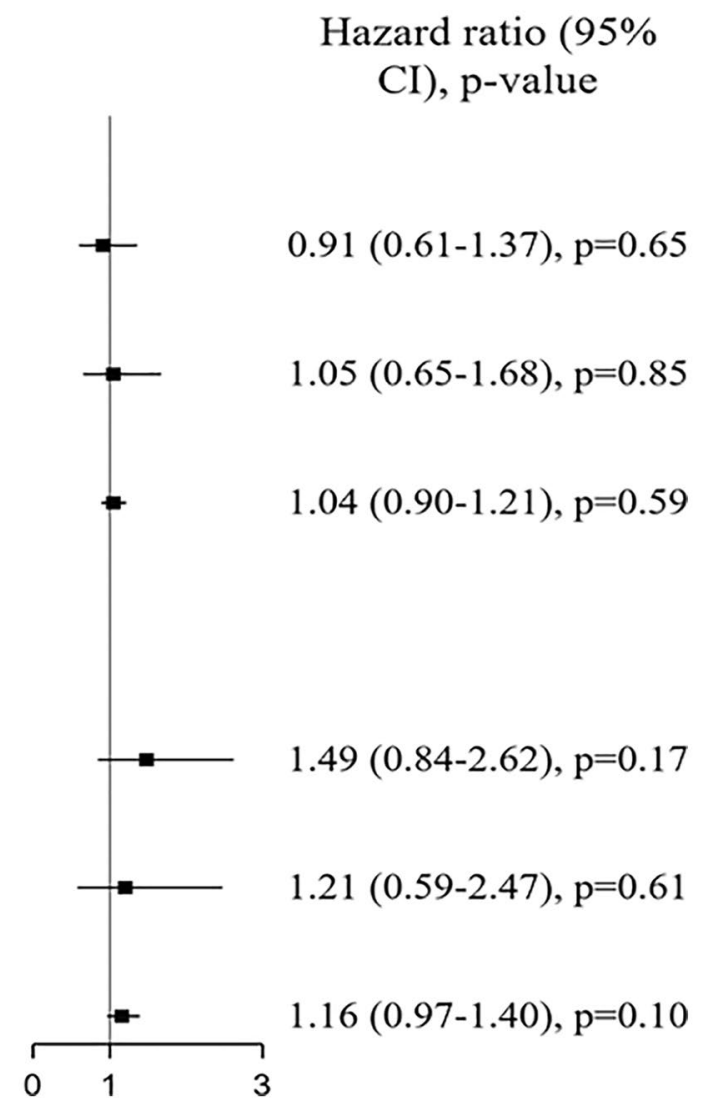

Fig. 2 Adjusted MCRI, CRBSI and colonization hazard risk for off-hours in CVCs and ACs. Cl: confidence interval. MCRI: major catheter-related bloodstream infection. CRBSI: catheter-related bloodstream infection. CVC: central venous catheter. AC: arterial catheter. A hazard ratio (HR) > 1 indicated an increased risk for off-hours compared to on-hours. Adjustment variables were the following: gender, SAPS II, insertion site, experience of the operator, skin antisepsis, CHG-impregnated dressings, time from ICU admission to catheter insertion, mechanical ventilation and vasopressor at insertion

Table 3 Skin colonization at catheter removal

\begin{tabular}{|c|c|c|c|}
\hline & On-hours & Off-hours & $p$-value \\
\hline \multicolumn{4}{|c|}{ Skin colonization at removal $(n=9478)$} \\
\hline $\begin{array}{l}\text { High-grade coloniza- } \\
\text { tion }\end{array}$ & $1520(31.2)$ & $1328(28.9)$ & \multirow[t]{3}{*}{$<0.01$} \\
\hline $\begin{array}{l}\text { Low-grade coloniza- } \\
\text { tion }\end{array}$ & $1429(29.3)$ & $1302(28.3)$ & \\
\hline Sterile & $1929(39.5)$ & $1970(42.8)$ & \\
\hline \multicolumn{4}{|c|}{ Skin colonization at removal, $\leq 4$ catheter-days $(n=4129)$} \\
\hline $\begin{array}{l}\text { High-grade coloniza- } \\
\text { tion }\end{array}$ & $441(23.2)$ & $475(21.3)$ & \multirow[t]{3}{*}{0.11} \\
\hline $\begin{array}{l}\text { Low-grade coloniza- } \\
\text { tion }\end{array}$ & $570(30)$ & $642(28.8)$ & \\
\hline Sterile & $887(46.7)$ & $1114(49.9)$ & \\
\hline \multicolumn{4}{|c|}{ Skin colonization at removal, $>4$ catheter-days $(n=5349)$} \\
\hline $\begin{array}{l}\text { High-grade coloniza- } \\
\text { tion }\end{array}$ & $1079(36.2)$ & $853(36)$ & \multirow[t]{3}{*}{0.62} \\
\hline $\begin{array}{l}\text { Low-grade coloniza- } \\
\text { tion }\end{array}$ & $859(28.8)$ & $660(27.9)$ & \\
\hline Sterile & $1042(35)$ & $856(36.1)$ & \\
\hline
\end{tabular}

results were observed for skin colonization at insertion site in catheters with short duration of catheter maintenance (i.e., $<4$ days), probably reflecting a similar extraluminal contaminations between both groups. Importantly, comparing catheters with long duration (i.e., $>4$ or 6 days) we did not detect any differences in infectious risk between on- and off-hours. In light of these considerations, we believe that catheters inserted during off-hours should be managed in a similar way as catheters inserted during on-hours and should probably not be removed early.

Intravascular catheters were more frequently inserted in the femoral vein or artery during offhours. Interestingly, after excluding subclavian catheters (i.e., insertion site with well-established reduced infectious risk), neither arterial nor venous femoral site increased the intravascular catheter risk of infection (MCRI and CRBSI) during off-hours. However, the catheter tip colonization risk increased in femoral inserted catheters. This result should be interpreted 
with caution. We described that catheter tip colonization showed poor agreement with intravascular catheter infections (i.e., CRBSI) and, probably, catheter tip colonization reflected an unsuitable surrogate marker for intravascular catheter infections [24]. In light of these results, we discourage routine replacement of intravascular catheters inserted in the femoral site during off-hours.

Our analysis has several limitations. First, we performed an observational study of prospectively collected RCT data, patients could not be randomized according to our interest variable and unmeasured factors may persist, thus causing residual confounding. However, this high-quality database allowed us to adjust for several confounders. Second, infection prevention and control (IPC) measures in patients included in RCT were probably better implemented than IPC measures under reallife conditions. It is therefore conceivable that results may differ when considering patients not included in RCTs. Third, the original RCTs were designed to investigate the impact of certain infection prevention measures, and interactions may have occurred among the study groups or centers. However, our statistical analyses considered these potential drawbacks and our models were stratified by centers. Fourth, our interest variable (on- versus offhours) was based on French policies, which may limit the generalizability of our results to other countries. Fifth, we could analyze at catheter level the impact of staffing (e.g., resident or advanced practice providers alone without senior physicians) on intravascular catheter infections. On the other hand, intravascular catheters were inserted by more experienced operators during off-hours, thus mitigating the impact of off-hours on the main results. However, our models considered the experience of the operator as adjustment factor.

\section{Conclusions}

In ICUs where catheter-infection prevention measures are fully implemented, insertion during off-hours was not associated with an increased risk of infections compared to catheters inserted during on-hours. Off-hours insertion is not a sufficient reason for early catheter removal, even if femoral route has been selected.

\footnotetext{
Abbreviations

AC: Peripheral arterial catheter.; CoNS: Coagulase-negative staphylococci.; CRBSI: Catheter-related bloodstream infections.; CVC: Central venous catheter and short-term dialysis catheter.; DC: Short-term dialysis catheter; HR: Hazard ratio.; ICU: Intensive care unit.; IPC: Infection prevention and control.; IQR: Interquartile range.; MCRI: Major catheter-related infection.; RCT: Randomized controlled-trial.; SOFA: Sepsis-related Organ Failure Assessment.
}

\section{Supplementary Information}

The online version contains supplementary material available at https://doi. org/10.1186/s13613-021-00940-3.

Additional file 1. Practices and intravascular catheter infection during onand off-hours in critically ill patients.

\section{Acknowledgements}

The authors thank Céline Féger, M.D., (EMIBiotech) for her editorial support.

\section{Authors' contributions}

$\mathrm{NB}, \mathrm{SR}, \mathrm{AM}, \mathrm{CD}$ and JFT analyzed and interpreted the data. OM, BS, JCL, OM were responsible for the data collection. NB and JFT were the major contributors in writing the manuscript. All authors read and approved the final manuscript.

\section{Funding}

NB is currently receiving a Mobility grant from the Swiss National Science Foundation (Grant Number: P4P4PM_194449). This grant supports his fellowship in Geneva.

\section{Availability of data and materials}

The datasets used and/or analyzed during the current study are available from the corresponding author on reasonable request.

\section{Declarations}

Ethics approval and consent to participate

All studies were approved by the national ethics committees.

\section{Consent for publication}

Not applicable.

\section{Competing interests}

The authors have disclosed that they do not have competing interest. JFT received fees for lectures to $3 \mathrm{M}, \mathrm{MSD}$, Pfizer, and Biomerieux. JFT received research grants from Astellas, 3M, MSD, and Pfizer. JFT participated to advisory boards of 3M, MSD, Bayer Pharma, Nabriva, and Pfizer. OM received fees for lectures for $3 \mathrm{M}$ and $\mathrm{BD}$. $\mathrm{OM}$ received research grants from $\mathrm{BD}$. NB received research grant from Pfizer.

\section{Author details}

${ }^{1}$ University of Paris, INSERM, IAME, 75006 Paris, France. ${ }^{2}$ AP-HP, Infection Control Unit, Bichat- Claude Bernard University Hospital, 46 rue Henri Huchard, 75877 Paris Cedex, France. ${ }^{3}$ Medical and Infectious Diseases Intensive Care Unit, AP-HP, Bichat-Claude Bernard University Hospital, 46 rue Henri Huchard, 75877 Paris Cedex, France. ${ }^{4}$ Medical ICU, Gabriel-Montpied University Hospital, Clermont-Ferrand, France. ${ }^{5}$ Services des Urgences Adultes and SAMU 86, Centre Hospitalier Universitaire de Poitiers, 86021 Poitiers, France. ${ }^{6}$ Université de Poitiers, Poitiers, France. ${ }^{7}$ Inserm U1070, Poitiers, France. ${ }^{8}$ Infection Control Program and WHO Collaborating Centre On Patient Safety, University of Geneva Hospitals and Faculty of Medicine, Geneva, Switzerland.

Received: 5 August 2021 Accepted: 17 October 2021

Published online: 29 October 2021

\section{References}

1. ECDC Healthcare-associated infections acquired in intensive care units. https://www.ecdc.europa.eu/sites/default/files/documents/AER_for_ 2017-HAl.pdf. Accessed 23 Mar 2021. 
2. Adrie C, Garrouste-Orgeas M, Ibn Essaied W, Schwebel C, Darmon M, Mourvillier B, Ruckly S, Dumenil AS, Kallel H, Argaud L, Marcotte G, Barbier F, Laurent V, Goldgran-Toledano D, Clec'h C, Azoulay E, Souweine B, Timsit JF, Group* OS. Attributable mortality of ICU-acquired bloodstream infections: impact of the source, causative micro-organism, resistance profile and antimicrobial therapy. J Infect. 2017;74(2):131-41. https://doi.org/10. 1016/j.jinf.2016.11.001.

3. Zimlichman E, Henderson D, Tamir O, Franz C, Song P, Yamin CK, Keohane C, Denham CR, Bates DW. Health care-associated infections: a metaanalysis of costs and financial impact on the US health care system. JAMA Intern Med. 2013;173(22):2039-46. https://doi.org/10.1001/jamaintern med.2013.9763.

4. Ziegler MJ, Pellegrini DC, Safdar N. Attributable mortality of central line associated bloodstream infection: systematic review and meta-analysis. Infection. 2015;43(1):29-36. https://doi.org/10.1007/s15010-014-0689-y.

5. Schreiber PW, Sax H, Wolfensberger A, Clack L, Kuster SP, Swissnoso. The preventable proportion of healthcare-associated infections 2005-2016: systematic review and meta-analysis. Infect Control Hosp Epidemiol. 2018;39(11):1277-95. https://doi.org/10.1017/ice.2018.183.

6. Mizuno S, Kunisawa S, Sasaki N, Fushimi K, Imanaka Y. Effects of nighttime and weekend admissions on in-hospital mortality in acute myocardial infarction patients in Japan. PLoS ONE. 2018;13(1): e0191460. https:// doi.org/10.1371/journal.pone.0191460.

7. Timsit JF, Schwebel C, Bouadma L, Geffroy A, Garrouste-Orgeas M, Pease S, Herault MC, Haouache H, Calvino-Gunther S, Gestin B, Armand-Lefevre L, Leflon V, Chaplain C, Benali A, Francais A, Adrie C, Zahar JR, Thuong M, Arrault X, Croize J, Lucet JC, Dressing Study G. Chlorhexidine-impregnated sponges and less frequent dressing changes for prevention of catheter-related infections in critically ill adults: a randomized controlled trial. JAMA. 2009;301 (12):1231-41. https://doi.org/10.1001/jama.2009.376.

8. Timsit JF, Mimoz O, Mourvillier B, Souweine B, Garrouste-Orgeas M, Alfandari S, Plantefeve G, Bronchard R, Troche G, Gauzit R, Antona M, Canet E, Bohe J, Lepape A, Vesin A, Arrault X, Schwebel C, Adrie C, Zahar $J$ J, Ruckly S, Tournegros C, Lucet JC. Randomized controlled trial of chlorhexidine dressing and highly adhesive dressing for preventing catheter-related infections in critically ill adults. Am J Respir Crit Care Med. 2012;186(12):1272-8. https://doi.org/10.1164/rccm.201206-1038OC.

9. Souweine B, Lautrette A, Gruson D, Canet E, Klouche K, Argaud L, Bohe J, Garrouste-Orgeas M, Mariat C, Vincent F, Cayot S, Cointault O, Lepape A, Guelon D, Darmon M, Vesin A, Caillot N, Schwebel C, Boyer A, Azoulay E, Bouadma L, Timsit JF. Ethanol lock and risk of hemodialysis catheter infection in critically ill patients. A randomized controlled trial. Am J Respir Crit Care Med. 2015;191(9):1024-32. https://doi.org/10.1164/rccm. 201408-14310C

10. Mimoz O, Lucet JC, Kerforne T, Pascal J, Souweine B, Goudet V, Mercat A, Bouadma L, Lasocki S, Alfandari S, Friggeri A, Wallet F, Allou N, Ruckly S, Balayn D, Lepape A, Timsit JF, investigators CLEAN. Skin antisepsis with chlorhexidine-alcohol versus povidone iodine-alcohol, with and without skin scrubbing, for prevention of intravascular-catheter-related infection (CLEAN): an open-label, multicentre, randomised, controlled, two-by-two factorial trial. Lancet. 2015;386(10008):2069-77. https://doi.org/10.1016/ S0140-6736(15)00244-5.

11. O'Grady NP, Alexander M, Burns LA, Dellinger EP, Garland J, Heard SO, Lipsett PA, Masur H, Mermel LA, Pearson ML, Raad II, Randolph AG, Rupp ME, Saint S, Healthcare Infection Control Practices Advisory C. Guidelines for the prevention of intravascular catheter-related infections. Clin Infect Dis. 2011;52(9):e162-193. https://doi.org/10.1093/cid/cir257.

12. Buetti N, Mimoz O, Mermel L, Ruckly S, Mongardon N, Dupuis C, Mira JP, Lucet JC, Megarbane B, Bailly S, Parienti JJ, Timsit JF. Ultrasound guidance and risk for central venous catheter-related infections in the ICU. A post hoc analysis of individual data of three multi-centric randomized trials. Clin Infect Dis. 2020. https://doi.org/10.1093/cid/ciaa1817.

13. Timsit JF, Baleine J, Bernard L, Calvino-Gunther S, Darmon M, Dellamonica J, Desruennes E, Leone M, Lepape A, Leroy O, Lucet JC, Merchaoui Z, Mimoz O, Misset B, Parienti JJ, Quenot JP, Roch A, Schmidt M, Slama M, Souweine B, Zahar JR, Zingg W, Bodet-Contentin L, Maxime V. Expert consensus-based clinical practice guidelines management of intravascular catheters in the intensive care unit. Ann Intensive Care. 2020;10(1):118. https://doi.org/10.1186/s13613-020-00713-4

14. Timsit JF. Updating of the 12th consensus conference of the Societe de Reanimation de langue francaise (SRLF): catheter related infections in the intensive care unit. Ann Fr Anesth Reanim. 2005;24(3):315-22. https://doi. org/10.1016/j.annfar.2004.12.022.

15. Brun-Buisson C, Abrouk F, Legrand P, Huet Y, Larabi S, Rapin M. Diagnosis of central venous catheter-related sepsis. Critical level of quantitative tip cultures. Arch Intern Med. 1987;147(5):873-7.

16. Blot F, Nitenberg G, Chachaty E, Raynard B, Germann N, Antoun S, Laplanche A, Brun-Buisson C, Tancrede C. Diagnosis of catheter-related bacteraemia: a prospective comparison of the time to positivity of hubblood versus peripheral-blood cultures. Lancet. 1999;354(9184):1071-7. https://doi.org/10.1016/s0140-6736(98)11134-0.

17. Buetti N, Timsit JF. Management and prevention of central venous catheter-related infections in the ICU. Seminars Respir Crit Care Med. 2019;40(4):508-23. https://doi.org/10.1055/s-0039-1693705.

18. Buetti N, Ruckly S, Lucet JC, Mimoz O, Souweine B, Timsit JF. Short-term dialysis catheter versus central venous catheter infections in ICU patients: a post hoc analysis of individual data of 4 multi-centric randomized trials. Intensive Care Med. 2019;45(12):1774-82. https://doi.org/10.1007/ s00134-019-05812-w.

19. Gardella TJ, Rubin D, Abou-Samra AB, Keutmann HT, Potts JT Jr, Kronenberg HM, Nussbaum SR. Expression of human parathyroid hormone-(1-84) in Escherichia coli as a factor X-cleavable fusion protein. J Biol Chem. 1990;265(26):15854-9.

20. Bell CM, Redelmeier DA. Mortality among patients admitted to hospitals on weekends as compared with weekdays. N Engl J Med. 2001;345(9):663-8. https://doi.org/10.1056/NEJMsa003376.

21. Nemeth S, Schnell S, Argenziano M, Ning Y, Kurlansky P. Daytime variation does not impact outcome of cardiac surgery: results from a diverse, multi-institutional cardiac surgery network. J Thorac Cardiovasc Surg. 2019. https://doi.org/10.1016/j.jtcvs.2019.11.131.

22. Sommerstein R, Marschall J, Kuster SP, Troillet N, Carrel T, Eckstein FS, Widmer AF, Swissnoso. Cardiovascular daytime varying effect in cardiac surgery on surgical site infections and 1-year mortality: a prospective cohort study with 22,305 patients. Infect Control Hosp Epidemiol. 2019;40(6):727-8. https://doi.org/10.1017/ice.2019.89.

23. Montaigne D, Marechal X, Modine T, Coisne A, Mouton S, Fayad G, Ninni S, Klein C, Ortmans S, Seunes C, Potelle C, Berthier A, Gheeraert C, Piveteau C, Deprez R, Eeckhoute J, Duez H, Lacroix D, Deprez B, Jegou B, Koussa M, Edme JL, Lefebvre P, Staels B. Daytime variation of perioperative myocardial injury in cardiac surgery and its prevention by RevErbalpha antagonism: a single-centre propensity-matched cohort study and a randomised study. Lancet. 2018;391(10115):59-69. https://doi.org/ 10.1016/S0140-6736(17)32132-3.

24. de Grooth HJ, Timsit JF, Mermel L, Mimoz O, Buetti N, du Cheyron D, Oudemans-van Straaten HM, Parienti JJ, Sites C, groups D. Validity of surrogate endpoints assessing central venous catheter-related infection: evidence from individual- and study-level analyses. Clin Microbiol Infect. 2020;26(5):563-71. https://doi.org/10.1016/j.cmi.2019.09.022.

\section{Publisher's Note}

Springer Nature remains neutral with regard to jurisdictional claims in published maps and institutional affiliations.

\section{Submit your manuscript to a SpringerOpen ${ }^{\circ}$ journal and benefit from:}

- Convenient online submission

- Rigorous peer review

- Open access: articles freely available online

- High visibility within the field

Retaining the copyright to your article

Submit your next manuscript at $\mathbf{s p r i n g e r o p e n . c o m ~}$ 